\title{
MidgEmerge, a new predictive tool, indicates the presence of multiple emergence phenotypes of the overwintered generation of swede midge
}

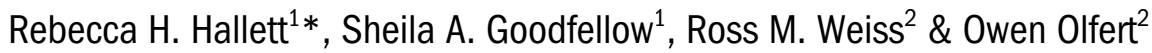 \\ ${ }^{1}$ Department of Environmental Biology, University of Guelph, Guelph, ON, Canada N1G 2W1, and ${ }^{2}$ Agriculture and \\ Agri-Food Canada, Saskatoon Research Centre, 107 Science Place, Saskatoon, SK, Canada S7N OX2 \\ Accepted: 17 September 2008
}

Key words: Contarinia nasturtii, DYMEX ${ }^{\mathrm{TM}}$, Contapré, insect management, predictive modelling, Diptera, Cecidomyiidae, Cruciferae, Brassicaceae

\begin{abstract}
The swede midge, Contarinia nasturtii (Kieffer) (Diptera: Cecidomyiidae), is a pest of cruciferous crops (Brassicaceae) in Europe and North America with high potential for economic impact. Effective timing of insecticide applications for swede midge control is difficult, in part due to a short adult lifespan. Predictive models are often used in integrated pest management programmes to facilitate the timing of control strategies. A European model, Contapré, for predicting adult swede midge emergence was shown to be inaccurate under Ontario field conditions. A new predictive model, MidgEmerge, was developed using DYMEX ${ }^{\mathrm{TM}}$ modelling software. MidgEmerge accurately predicts swede midge emergence in both Ontario and Québec. Observed emergence patterns cannot be explained without the presence of multiple emergence phenotypes. MidgEmerge indicates that there are two emergence phenotypes of the swede midge, each completing four generations per year in southern Ontario. A fifth generation of each may become possible with climate change. Evidence of a possible third emergence phenotype is presented. MidgEmerge has the potential to be an important predictive tool to inform and direct integrated pest management practices targeted against swede midge in North America.
\end{abstract}

\section{Introduction}

In its native Eurasia, the swede midge, Contarinia nasturtii (Kieffer) (Diptera: Cecidomyiidae), is an occasional serious pest of cruciferous vegetables (Brassicaceae), along with two other midges, the brassica pod midge, Dasyneura brassicae (Winnertz), and a flower gall midge, Gephyraulus raphanistri (Kieffer) (Barnes, 1946). Felt (1925) expressed concern that conditions in North America were favourable for the establishment of swede midge and that serious economic losses could result. In 2000, swede midge was first identified in North America in several cole crop (i.e., cultivars of Brassica oleracea L.) fields in Ontario, Canada, where growers experienced up to $85 \%$ yield losses (Hallett \& Heal, 2001).

*Correspondence: Rebecca H. Hallett, Department of Environmental Biology, University of Guelph, Guelph, ON, Canada N1G 2W1.

E-mail: rhallett@uoguelph.ca
Most of Canada appears suitable for establishment of swede midge, with high population growth possible in parts of British Columbia, Ontario, Québec, New Brunswick, Nova Scotia, and Prince Edward Island (Olfert et al., 2006). The range of swede midge in Ontario (Canadian Food Inspection Agency, 2007) has now expanded to all of the areas projected by Olfert et al. (2006) to be 'very favourable' for establishment, and its range may still expand significantly. For example, swede midge was confirmed to be present in western Canada (Saskatchewan) and Nova Scotia in 2007 (Canadian Food Inspection Agency, 2008). The Canadian Food Inspection Agency (2002) has declared swede midge to be a serious pest with a medium overall risk rating, but high potential for economic impact.

Limited information on swede midge population dynamics complicates the development of an integrated pest management (IPM) programme for this pest. Effective timing of insecticide applications for control of swede midge is difficult due to the short adult lifespan and concealed 
nature of larval feeding (Taylor, 1912; Smith, 1951; Frey et al., 2004). Effective control of first-emerging adults and first-generation larvae is critical in order to reduce field populations of the swede midge (International Swede Midge Task Force, 2005). With only two active ingredients (cyhalothrin lambda and acetamiprid) registered for use against swede midge in Canada (Registration numbers 24984.00 and 27128.00, respectively; Pest Management Regulatory Agency, 2006) and multiple generations per year (Goodfellow, 2005; Hallett et al., 2007), there is a high risk of swede midge evolving insecticide resistance. An IPM programme may help delay or prevent the development of insecticide resistance through the integration of cultural practices and proper timing of insecticide applications. The ability to predict the presence of adult and larval life stages accurately would help growers to time insecticide applications optimally and to select an insecticide with efficacy against the prevailing life stage (Ridsdill-Smith et al., 2005). This practice will help to minimize the unnecessary use of insecticides and to slow the development of insecticide resistance in this pest.

In southern Ontario, overwintered swede midges apparently emerge in $2-3$ peaks (early June, mid-late June, mid July), with some emergence continuing until mid-August (Goodfellow, 2005; Hallett et al., 2007). Emergence of the overwintered generation from June to August has been observed in Norway (Rygg \& Braekke, 1980). Prolonged emergence and the likely presence of multiple emergence phenotypes has complicated efforts to determine the number of generations occurring per year in this region, but also makes it difficult to target control measures at the emerging overwintered population.

Predictive models based on degree-day (DD) accumulations are used to predict a variety of biological events, including plant flowering, insect oviposition, egg hatch, and adult insect emergence, and they are often used in IPM programmes (Davis \& Pedigo, 1991; Borchert et al., 2004; Broatch et al., 2006). The Contapré model is a DD-based model developed in Europe for predicting emergence of adult swede midge (Bouma, 1996). The average daily soil temperature at $5-\mathrm{cm}$ soil depth and a lower threshold value of $7.2^{\circ} \mathrm{C}$ for development are used to determine when adults will be flying. The model was tested under irrigated field conditions in Germany and was shown to be accurate within 2-3 days (Koch \& Gemmar, 2002).

Models developed with DYMEX ${ }^{\mathrm{TM}}$ modelling software (Maywald et al., 2003, 2004) can integrate a number of factors, including rainfall and soil moisture, that affect swede midge life history. The objectives of this study were (1) to evaluate the accuracy of the Contapré model in predicting swede midge emergence in non-irrigated fields in Ontario, Canada, (2) to develop a new predictive model for swede midge emergence using $\mathrm{DYMEX}^{\mathrm{TM}}$, (3) to determine whether observed emergence patterns were best explained by single or multiple emergence phenotypes, and (4) to determine the number of generations of swede midge occurring per year in southern Ontario.

\section{Materials and methods}

\section{Population monitoring}

Data on abundance of swede midge adults were obtained from ten emergence (2003 and 2004) and three pheromone (2004) traps (Hallett et al., 2007) established at each of two sites in southern Ontario, Canada (Markham, $43^{\circ} 54^{\prime} \mathrm{N}$, $79^{\circ} 22^{\prime} \mathrm{W}$; and Stouffville, $43^{\circ} 58^{\prime} \mathrm{N}, 79^{\circ} 16^{\prime} \mathrm{W}$ ). In 2003 , traps were monitored daily from 10 May to 10 October, and in 2004, traps were monitored three times a week from 28 April to 3 September, and then twice a week until 20 October. Larval abundance data from Laval, Québec $\left(45^{\circ} 35^{\prime} \mathrm{N}\right.$, $73^{\circ} 40^{\prime} \mathrm{W}$ ), in 2004 were kindly provided by Favio Corlay (Université Laval, Québec) and Dr Guy Boivin (Horticulture Research and Development Centre, Agriculture and Agri-Food Canada, Saint-Jean-sur-Richelieu, Québec). Every 2 days from 18 June to 29 October, 25 randomly selected broccoli plants were destructively sampled and all larvae counted. The mean number of larvae per plant was determined for each sampling date.

\section{Meteorological monitoring}

In-site weather data from both Ontario sites was used in testing the Contapré model. Soil temperature $\left({ }^{\circ} \mathrm{C}\right)$ and ambient air temperature $\left({ }^{\circ} \mathrm{C}\right)$ were recorded every $15 \mathrm{~min}$ using $\mathrm{HOBO}^{\circledR} \mathrm{H} 8$ Outdoor/Industrial 4-Channel External Loggers fitted with soil probes and $\mathrm{HOBO}^{\circledR} \mathrm{H} 8$ Pro Series r.h./Temp loggers (Hoskin Scientific, Burlington, Ontario, Canada), respectively. Loggers were protected from solar radiation and rain within a ventilated shield placed at a height of $1 \mathrm{~m}$. Soil probes were placed at $5-\mathrm{cm}$ depth outside and inside an emergence trap to assess potential differences in microclimate caused by the cages. Loggers were in the field from 27 March to 10 October 2003 and 14 April to 20 October 2004. A single Davis Rain Collector II (Davis Instruments, Hayward, CA, USA) was placed at each site to monitor rainfall. Rain events were recorded in $0.2 \mathrm{~mm}$ increments using $\mathrm{HOBO}^{\circledR}$ Event Loggers (Hoskin Scientific). Rain collectors were placed at a height of $1 \mathrm{~m}$ and situated in the field from 7 May to 10 October 2003 and 14 April to 20 October 2004.

Meteorological data sets (daily maximum air temperature, minimum air temperature, and rainfall) from the nearest Environment Canada weather station to each of the field sites (Markham and Stouffville: Toronto-Buttonville, $43^{\circ} 52^{\prime} \mathrm{N}, 79^{\circ} 22^{\prime} \mathrm{W}$; Laval: Montréal, $45^{\circ} 47^{\prime} \mathrm{N}, 73^{\circ} 75^{\prime} \mathrm{W}$ ) 
were obtained from Environment Canada (2005) for use in the DYMEX ${ }^{\mathrm{TM}}$ model. Long-term normal relative humidity values (\%) at 09:00 and 15:00 hours for Toronto were obtained from a $0.5^{\circ}$ world grid dataset (New et al., 1999) provided with CLIMEX ${ }^{\mathrm{TM}} 2.0$ (Sutherst et al., 2004).

\section{Contapré}

The accumulation of DD in the Contapré model (Bouma, 1996) begins when the daily maximum soil temperature at 5-cm depth exceeds $20^{\circ} \mathrm{C}$ and $\geq 11 \mathrm{~mm}$ of rain follows within 3 days (M Vlaswinkel, pers. comm.). First flight of swede midge was predicted to occur when thermal accumulations (C) exceeded that required for necessary insect development to occur, and was described by the following equation of the Contapré model:

$$
\mathrm{C}=\sum_{\mathrm{t}}\left(\mathrm{T}-\mathrm{T}_{0}\right)
$$

where $\mathrm{t}=$ time (days), $\mathrm{T}=$ mean daily temperature at soil depth of $5 \mathrm{~cm}\left({ }^{\circ} \mathrm{C}\right)$, and $\mathrm{T}_{0}=$ base threshold of development $\left(7.2^{\circ} \mathrm{C}\right)$. $\mathrm{C}$ is calculated daily and summed to the previous day's value. When $\mathrm{C}$ reaches $160 \mathrm{DD}$, adult emergence should occur. Successive flights occur when $\mathrm{C}$ again reaches $160 \mathrm{DD}$. In addition, if the mean daily temperature over 2 days falls below $15^{\circ} \mathrm{C}$, flight is delayed until the mean daily temperature rises above this value; and, if more than $25 \mathrm{~mm}$ of precipitation falls between 135-160 DD, adult flight will occur immediately (M Vlaswinkel, pers. comm.).

The Contapré model was assessed for Ontario by entering soil temperature at $5 \mathrm{~cm}$ depth and rainfall data collected from each field site in 2003 and 2004 into equation 1 and comparing predicted values to observed emergence trap captures. The Contapré model predicts emergence as a single-day event, which should be reflected in an increase (or peak) in adult numbers relative to surrounding days. For visual comparison of predicted and observed peak days, a value of 1 was assigned to each observed or predicted peak day and a value of 0 assigned to all other days. For observed data, any day that had a higher number of midges captured than the previous and subsequent days, and that had mean captures greater than 0.2 midges per trap per day, was considered a population peak day. In order to assess goodness-of-fit of the model, a value of 1 was assigned to each observed or predicted peak day as well as to the day before and after the peak, 0.75 assigned to days that were 2 and 3 days removed from the peak, 0.25 assigned to days that were 4-6 days removed from the peak, and 0 assigned to all other days. All data were subjected to a $\log (\mathrm{x}+0.5)$ transformation (Yamamura, 1999) prior to conducting linear regression analyses (SAS, 1999). The resultant $r^{2}$ values were used as an indicator of the goodness-of-fit of the model. DD were obtained from the Contapré model using equation 1 for observed and predicted days of emergence and the difference between the two values was determined.

\section{MidgEmerge}

The new model, hereafter referred to as MidgEmerge, was developed with eight DYMEX ${ }^{\mathrm{TM}}$ modules (Maywald et al., 2003, 2004). A description of each module and its function is given below. The initialization date for the model was set at 1 January. The number of overwintering swede midge diapause larvae in the soil at the initialization date was arbitrarily set at 20 . Pheromone trap capture data from Markham in 2004 were used for parameterization of the model.

(1) Timer module. The module, which provides the timing for the model, runs on a daily time step and thus all parameters that follow are reported in days.

(2) Meteorological data. The module reads meteorological data from an external data file and controls the progression of the model. The variables 'daily maximum air temperature' $\left({ }^{\circ} \mathrm{C}\right)$, 'minimum air temperature' $\left({ }^{\circ} \mathrm{C}\right)$, 'rainfall' $(\mathrm{mm})$, and 'relative humidity' (\%) at 09:00 and 15:00 hours were included in this module.

(3) Latitude. The latitude module was constructed using the QueryUser module, which allows the modeller to input a latitude value at the beginning of the simulation. This value corresponded to the field site being modelled $\left(43^{\circ} \mathrm{N}\right.$ for Markham and Stouffville, and $45^{\circ} \mathrm{N}$ for Laval). The output of the latitude model was then used as an input to the daylength module.

(4) daylength. The daylength module accounts for the number of hours between sunrise and sunset and was calculated based on day of year and latitude. This module was used as an input to the daily temperature cycle module.

(5) Daily temperature cycle. A circadian module, which fits a temperature cycle to daily maximum and minimum temperatures, was used in the construction of the daily temperature module. The circadian module calculated a diurnal change in temperature using 24 steps, one for each hour of the day, by using daily maximum and minimum temperatures as well as daylength. Calculations are based on a composite (sine + exponential) curve interpolation. This interpolation assumes that the daily minimum temperature occurs before the maximum temperature and that the maximum temperature is reached before sunset. A sine curve was used from each daily minimum temperature until sunset and an exponential decay curve was used for the remainder of the day. This module drives the temperature-dependent developmental rates included in the life cycle module described below. 
(6) 7-Day precipitation. An individual rainfall event may have lasting effects on the moisture level in the soil beyond the day the rainfall event occurred. For that reason, a 7-day precipitation value was calculated using the RunMean module. Total rainfall was used as the input in this module. The output, 7-day total precipitation, was calculated by totalling the rainfall over the current and previous six timesteps. This value was used in the 'pupa to adult' transfer stage (see below).

(7) Running mean temperature. A 21-day average temperature was calculated using the RunMean module. Temperature was the only input variable and the output, running mean temperature, was calculated by averaging the temperature for the current and previous 20 timesteps. Running mean temperatures for 7 and 14 days were also tested, but 21 days was found to yield the best predictive results (Goodfellow, 2005).

(8) Life cycle. The life cycle module simulates swede midge population dynamics on a cohort basis. In $\mathrm{DYMEX}^{\mathrm{TM}}$, a cohort is considered to be a group of individuals that enter a life stage at the same time and that experience the same conditions. Various life processes, such as developmental rate, mortality, reproduction, and graduation (i.e., transfer from one life stage to the next) of each life stage (egg, larval, pupal, and adult) are included in the model.

Egg. Egg development, based on the daily temperature cycle, was modelled using a linear above threshold (LAT) function with the default threshold established at $9.5^{\circ} \mathrm{C}$ and slope of 0.0449 . The parameter values were estimated by linear regression of developmental trials conducted at constant temperatures between 10 and $30^{\circ} \mathrm{C}$ (Readshaw, 1961). The following equation was obtained:

$D_{e}=0.0449 x-0.4262\left(n=344, r^{2}=0.967\right)$,

where $\mathrm{D}_{\mathrm{e}}=$ rate of egg development (/day) and $\mathrm{x}=$ temperature $\left({ }^{\circ} \mathrm{C}\right)$.

Graduation from the egg to the larval stage was based on the physiological age of the eggs using a step function with a threshold (i.e., the value of the driving variable, physiological age of the eggs, at which the step occurs) of 1 and the step height (i.e., the proportion of eggs graduating to the larval stage) set at 1 . Physiological age is measured as the proportion of development completed by the individual and, in this case, all individuals proceed to the next life stage when they have experienced a fixed physiological time.

Larva. Larval development was modelled as an LAT function based on the daily temperature cycle. The threshold value of $11.5^{\circ} \mathrm{C}$ and slope of 0.0106 were estimated by linear regression of development data for temperatures between 15 and $25^{\circ} \mathrm{C}$ (Readshaw, 1961). The best-fit equation was:

$\mathrm{D}_{1}=0.0106 \mathrm{x}-0.1214\left(\mathrm{n}=50, \mathrm{r}^{2}=0.9999\right)$,

where $\mathrm{D}_{1}=$ rate of larval development (/day) and $\mathrm{x}=$ temperature $\left({ }^{\circ} \mathrm{C}\right)$.

A mortality factor was incorporated in this life stage as a continuous mortality process based on the chronological age of the individual larva using a step function. Continuous mortality is a process applied to each cohort at each timestep during the life of that cohort. The chronological age is a measure of the time an individual has spent in that life stage. The default threshold value was set to 28 days, as this was the maximum duration of the larval stage observed by Readshaw (1966), and the step height (i.e., the proportion of individuals dying after 28 days) to 1 .

Larvae that survived either graduated to the pupal stage or entered diapause. For graduation to the pupal stage, a step function based on the physiological age of the cohort was used with default values for the threshold and the step height (proportion of individuals graduating) both set to 1. Induction to the diapause larval stage was modelled as a linear below-threshold function using day length, with a threshold value of $13.5 \mathrm{~h}$ and a slope of -1 . The diapauseinduction daylength was determined once all other parameters were established by examination of predicted peaks and last occurrence of adults in the fall with threshold values set between $12-14 \mathrm{~h}$.

Diapause larva. Development of diapause larvae was modelled as a step function based on the daily temperature cycle with the default value for the development threshold set to $6.5^{\circ} \mathrm{C}$ and the step height set to 1 . The threshold value was selected, because it permitted first occurrence of adults in mid-May, whereas a threshold value of $6{ }^{\circ} \mathrm{C}$ resulted in an 8-day delay to the first occurrence of adults.

Transition from the diapause larval stage to the pupal stage was modelled using a two-condition combination (product) rule, meaning that both conditions must be satisfied for development to progress. The first condition, chronological age of diapause larvae, was modelled using a step function with a threshold value of 60 and a step height of 1. With 1 January as initialization date, the 60-day threshold corresponds to the required 150 diapausedevelopment days estimated by Olfert et al. (2006) from early October. The second condition, diapause-termination temperature, was modelled using a step function based on the 7-day average minimum temperature with a threshold of $4{ }^{\circ} \mathrm{C}$ and a step height of 0.75 (proportion of individuals terminating diapause when the threshold was exceeded). 
Pupa. Pupal development was modelled as an LAT function based on the daily temperature cycle. Because the model was parameterized using captures of males on pheromone traps, male developmental parameters were initially used with a default threshold value (minimum temperature for growth) of $7.1^{\circ} \mathrm{C}$ and a slope of 0.007 . These values (and default threshold values of 6.5 and $6.8^{\circ} \mathrm{C}$ for females and the average of males and females combined, respectively) were estimated from linear regressions of data for temperatures between $12-30{ }^{\circ} \mathrm{C}$ (Readshaw, 1961), and the following equations were obtained:

$\mathrm{D}_{\text {ठै } \mathrm{p}}=0.0055 \mathrm{x}-0.0389\left(\mathrm{n}=268, \mathrm{r}^{2}=0.993\right)$,

$\mathrm{D}_{\text {क }}=0.0051 \mathrm{x}-0.0331\left(\mathrm{n}=389, \mathrm{r}^{2}=0.992\right)$, and

$\mathrm{D}_{\text {○ึ } q \mathrm{p}}=0.0053 \mathrm{x}-0.0359\left(\mathrm{n}=657, \mathrm{r}^{2}=0.993\right)$,

where $\mathrm{D}_{\delta \mathrm{p}}=$ rate of male pupal development (/day), $\mathrm{D}_{q \mathrm{p}}=$ rate of female pupal development $(/$ day $), \mathrm{D}_{\delta \uparrow \mathrm{p}}=$ rate of combined male and female pupal development (/day), and $\mathrm{x}=$ temperature $\left({ }^{\circ} \mathrm{C}\right)$. The slope for males was adjusted from 0.0055 to 0.007 in order to obtain a first predicted peak of adults in mid-May, rather than in the 3rd week of May.

Graduation from the pupal to adult stage was modelled using a two-condition combination (product) rule. The first condition was a step function based on physiological age of the individual. The threshold and step height (proportion of pupae graduating to the adult stage) were both set at 1 . Moisture is critical for adult emergence (Readshaw, 1961), so a step function based on 7-day total rainfall was included as the second condition. The threshold height was set at $6 \mathrm{~mm}$, because this allowed emergence of adults in mid-May, and the step height was 1 (proportion of pupae graduating to the adult stage).

Adult. Adult development was modelled based on chronological age using an LAT function with the threshold set to 1 and a slope of 1 . Adult mortality, based on chronological age, was included in the model using a step function with a threshold of 1 day and a step height (proportion of adults dying) of 0.25 .

Reproduction was modelled as two separate components, fecundity and production rate. Fecundity, the total number of possible offspring that an individual can produce, was modelled using a parameter of fecundity that is an 'establishment' process acting only once when the individual enters the life stage. The default value was set at 35 eggs, approximately half the typical egg production of a female swede midge (Readshaw, 1961), based on an assumed 1:1 sex ratio in the population. Progeny production was modelled using a two-condition combination (sum) rule, where both conditions contribute additively to the production of eggs. The first condition was a step function based on chronological age with a threshold of 0.5 days and a step height (number of eggs produced per day) of 1. Egg production was set at $1 \mathrm{egg} /$ day in order to limit population size, as extrinsic mortality factors (insecticide applications, natural enemies, etc.) are not included in the model. The second condition, minimum temperature for egg production, was modelled using an LAT function with a default threshold of $16^{\circ} \mathrm{C}$ and a slope of 1 , as Stokes (1953) reported that oviposition occurs between $16-26{ }^{\circ} \mathrm{C}$.

Developmental parameters. In order to determine whether it was necessary to use different developmental parameters in the model based upon the type of trapping data available (e.g., males for pheromone trap data, male and female averages for emergence trap data), model runs using either a default value for the minimum temperature threshold for pupal development of 7.1 or $6.8^{\circ} \mathrm{C}$ were compared.

\section{Emergence phenotypes}

After initial parameterization of the model, as described above, iterative alterations to the model were made to simulate a second emergence phenotype that would emerge in mid-June, thus matching observed peaks (11-14 and 16-18 June) at Markham in 2004. Different threshold values were tested for the transition between diapause larval and pupal stages (7-day average minimum temperatures of $6,7,10,12$, and $14{ }^{\circ} \mathrm{C}$ ), the minimum temperature for pupal growth (daily temperature cycle of $10^{\circ} \mathrm{C}$ ), the rainfall effect on the pupal to adult stage transition (7-day total rainfall of $8.5,10,12$, and $16 \mathrm{~mm}$ ), and the number of required diapause development days for diapause larvae (chronological ages of 90, 120, 130, 140, 150, and 160 days from 1 January). Comparisons were then made between the model initialized with 20 diapause larvae with 60 required diapause development days, initialized with 10 diapause larvae at both 60 and 140 diapause development days, and with 10 diapause larvae at 60, 140, and 160 diapause development days.

\section{Model parameterization and validation}

Pheromone trap capture data from Markham in 2004 were used for parameterization of the model. Pheromone trap data from Stouffville in 2004, emergence trap data from Markham and Stouffville in 2003, and larval data from Laval in 2004 were used for model validation. As pheromone trap data were collected three times a week, the mean predicted number of adults per day was calculated from the predicted daily numbers for the same 2-3-day periods as pheromone data. As pheromone trap counts were 
usually made mid-morning, after morning activity of swede midge, predicted numbers for the 1st day of a given time period were ascribed to the previous time period (e.g., predicted numbers on 17 May were counted in the 14-17 May period, rather than in the 17-19 May period). Mean predicted larval numbers were calculated from predicted daily numbers for the same time periods as larval data from Laval. Daily predicted and observed values were used for model validation for 2003. Any time interval or day that had a higher number of midges (observed or predicted) than the previous and subsequent time intervals was considered a peak. For visual comparison of predicted and observed peaks, a value of 1 was assigned to each observed or predicted peak and a value of 0 assigned to all other time intervals or days. To assess goodness-of-fit of the model, a value of 1 was assigned to time intervals with an observed or predicted peak, 0.75 assigned to one time interval on each side of a peak, 0.25 assigned to each of the time intervals twice removed from a peak, and 0 assigned to all other intervals. For daily data in 2003, a value of 1 was assigned to each observed or predicted peak day as well as to the day before and after the peak, 0.75 assigned to days that were 2 and 3 days removed from the peak, 0.25 assigned to days that were 4-6 days removed from the peak, and 0 assigned to all other days. All data were subjected to log $(\mathrm{x}+0.5)$ transformation prior to conducting linear regression analyses (SAS, 1999). The resultant $r^{2}$ values were used as an indicator of the goodness-of-fit of the model.

The proportion of observed peaks that occurred within 1-3 days of a predicted peak (i.e., same or one neighbouring trapping period), and that occurred within $1-5$ days (i.e., same, one or two neighbouring trapping periods) of a predicted peak were calculated. Predicted and observed swede midge numbers $(x+0.5)$ were plotted on a log scale for visual comparison of peaks and population trends. Model output and weather data (Figures 1 and 2) were examined to explain why any observed peaks were not predicted by the model.

\section{Results}

Contapré

Soil temperature readings inside emergence traps were cooler than readings outside emergence traps at both Markham (by 0.18 and $0.04{ }^{\circ} \mathrm{C}$ in 2003 and 2004, respectively) and Stouffville (by 0.18 and $0.16^{\circ} \mathrm{C}$ in 2003 and 2004, respectively).

In 2003, first emergence occurred on 7 June and 27 May at Markham and Stouffville, respectively (Figure 3A,C). Based on the Contapré model, DD accumulations in 2003 began on 19 July $\left(20.8^{\circ} \mathrm{C}\right.$ with $10.6 \mathrm{~mm}$ of rain on 21 July) at Markham. At Stouffville, the required conditions to begin
DD accumulations were not met at any point in the season, so DD accumulations were calculated from 8 June $\left(17.3^{\circ} \mathrm{C}\right.$ with $16 \mathrm{~mm}$ of rain), which most closely approximated the required conditions. The Contapré model predicted five adult emergence peaks for Markham (30 July, 11 August, 23 August, 5 September, and 18 September) (Figure 3B) and eight for Stouffville (23 June, 4 July, 16 July, 29 July, 10 August, 22 August, 5 September, and 19 September) (Figure 3D). Goodness-of-fit values were very low and not statistically significant for comparisons of Contapré-predicted and observed values for both Markham $\left(\mathrm{r}^{2}=0.017, \mathrm{P}=0.18\right)$ and Stouffville $\left(r^{2}=0.010, P=0.29\right)$ in 2003. Similar results were obtained in 2004 (data not shown), when first emergence occurred on 26 May and 21 May at Markham and Stouffville, respectively, but it was not predicted by the Contapré model until 26 and 27 June, respectively. In 2004, $\mathrm{DD}$ accumulations began on 14 June at Markham $\left(20.3^{\circ} \mathrm{C}\right.$ with $40.6 \mathrm{~mm}$ of rain) and Stouffville $\left(20.3^{\circ} \mathrm{C}\right.$ with $33.4 \mathrm{~mm}$ of rain). The Contapré model predicted emergence peaks from 234.3 DD earlier to 1308.6 DD later than observed peaks over the 2-year study.

\section{MidgEmerge}

Parameterization. At the parameterization site (Markham, 2004), the last peak of adults was observed on 23-27 September and the last adults were captured on 7-11 October. A diapause-induction daylength threshold of $13 \mathrm{~h}$ or less allowed a strong peak in mid-October and occurrence of adults well into November, whereas a value of $14 \mathrm{~h}$ predicted the final peak on 10 September with the last adults present in early October. A threshold of $13.5 \mathrm{~h}$ was selected as it led to a smaller predicted peak in midOctober, and the last adults from the penultimate peak occurring until 9 October, which corresponded closely to the final observed capture period. Active larvae have been observed on plants in late September (data not shown), and all three threshold values predicted larval presence until late September.

The diapause-termination temperature was estimated to be $6{ }^{\circ} \mathrm{C}$ by Olfert et al. (2006); however, use of $6{ }^{\circ} \mathrm{C}$ as the threshold value here resulted in delay of the emergence of first adults until early June, whereas threshold values of 2 and $4{ }^{\circ} \mathrm{C}$ resulted in first emergence in mid-May. The threshold value of $4{ }^{\circ} \mathrm{C}$ was thus selected. For graduation from the pupal to adult stage, threshold values for 7-day total rainfall of 8.5 and $10 \mathrm{~mm}$ were examined in addition to $6 \mathrm{~mm}$, but resulted in too few predicted peaks.

Developmental parameters. The MidgEmerge model predicted six peaks of swede midge in 2004 parameterization runs, using either the male threshold value for minimum 
Figure 1 Rainfall (mm; bars, left y-axis) and mean ambient air temperature $\left({ }^{\circ} \mathrm{C}\right.$; circles, right $\mathrm{y}$-axis) values for (A) Markham in-site, (B) Stouffville in-site, and $(\mathrm{C})$ Environment Canada station at Toronto-Buttonville in 2003.
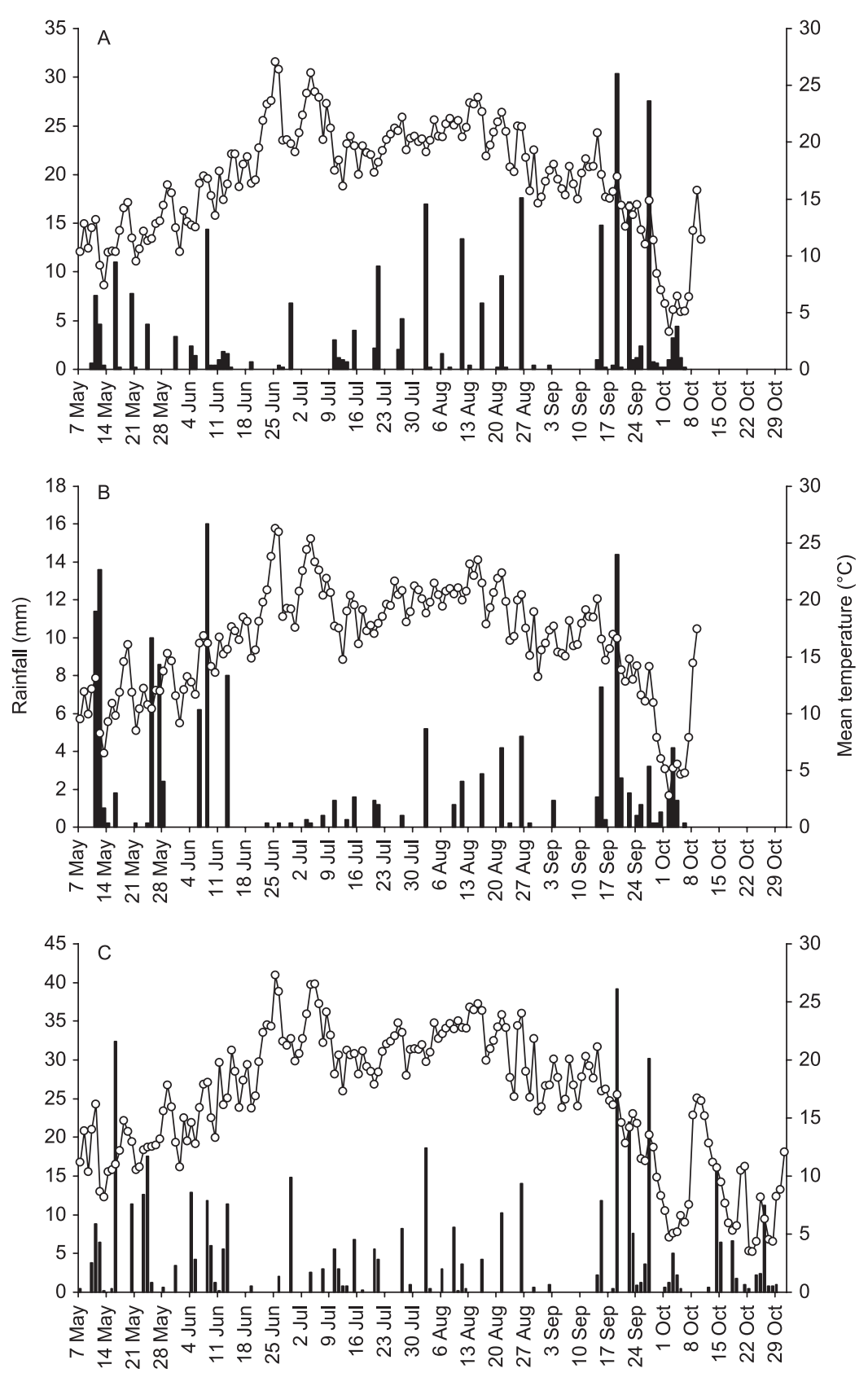

temperature for pupal growth $\left(7.1^{\circ} \mathrm{C}\right)$ or the average male and female threshold value $\left(6.8^{\circ} \mathrm{C}\right)$ when initialized with a single emergence phenotype requiring 60 diapause development days from 1 January (Figure 4). Use of the male threshold resulted in predicted peaks occurring within 3 days of $31.3 \%$ of the 16 observed peaks and within 5 days of $37.5 \%$ of observed peaks (Figure $4 \mathrm{~A}$ ). Both accuracy rates were increased to $43.75 \%$ with use of the average threshold value (Figure 4C). However, at least nine observed peaks were not predicted by the model when configured with only a single emergence phenotype. The goodness-of-fit value for the model run with the male threshold value $\left(\mathrm{r}^{2}=0.023, \mathrm{P}=0.23\right)$ was lower than that with the average threshold value $\left(\mathrm{r}^{2}=0.039, \mathrm{P}=0.12\right)$, but neither regression was statistically significant.

Emergence phenotypes. Manipulation of threshold values for the 7-day average minimum temperature requirement for the transition between diapause larval and pupal stages did not result in prediction of a peak as desired in mid- 

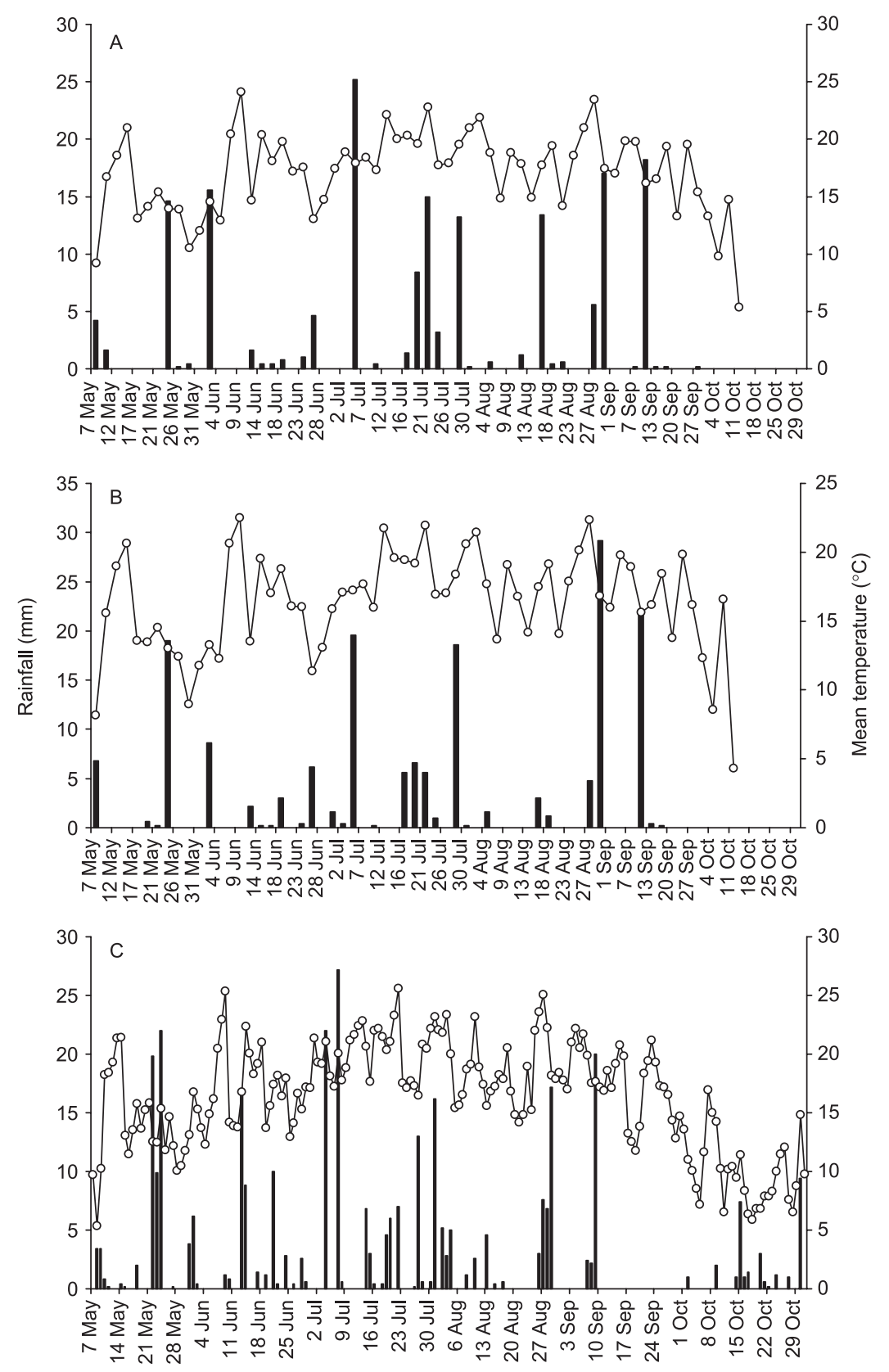

Figure 2 Rainfall (mm; bars, left y-axis) and mean ambient air temperature $\left({ }^{\circ} \mathrm{C}\right.$; circles, right $\mathrm{y}$-axis $)$ values for (A) Markham in-site, (B) Stouffville in-site, and $(\mathrm{C})$ Environment Canada station at Toronto-Buttonville in 2004.

June. Threshold values of $6-10{ }^{\circ} \mathrm{C}$ resulted in predicted first peaks in early June and values of $12-14{ }^{\circ} \mathrm{C}$ resulted in a predicted first peak after the end of June. Using a daily temperature cycle value of $10^{\circ} \mathrm{C}$ for the threshold value for minimum temperature for pupal growth delayed the first predicted peak to late May. Altering the rainfall threshold for the pupal to adult stage transition to $8.5,10,12$, and $16 \mathrm{~mm}$ (7-day total rainfall) had no effect on the timing of the first predicted peak. Alteration of the number of required diapause development days for diapause larvae to
$90,120,130,140,150$, and 160 days from 1 January resulted in the first predicted peaks occurring on 15 May, 25 May, 2 June, 14 June, 15 June, and 23 June, respectively. A requirement of 140 diapause development days was selected for the second emergence phenotype.

Incorporation of two emergence phenotypes into the model resulted in the prediction of 10 and 12 peaks of swede midge in 2004 using the male and average threshold values for minimum temperature for pupal growth, respectively (Figure 4). Using the male minimum temperature threshold 

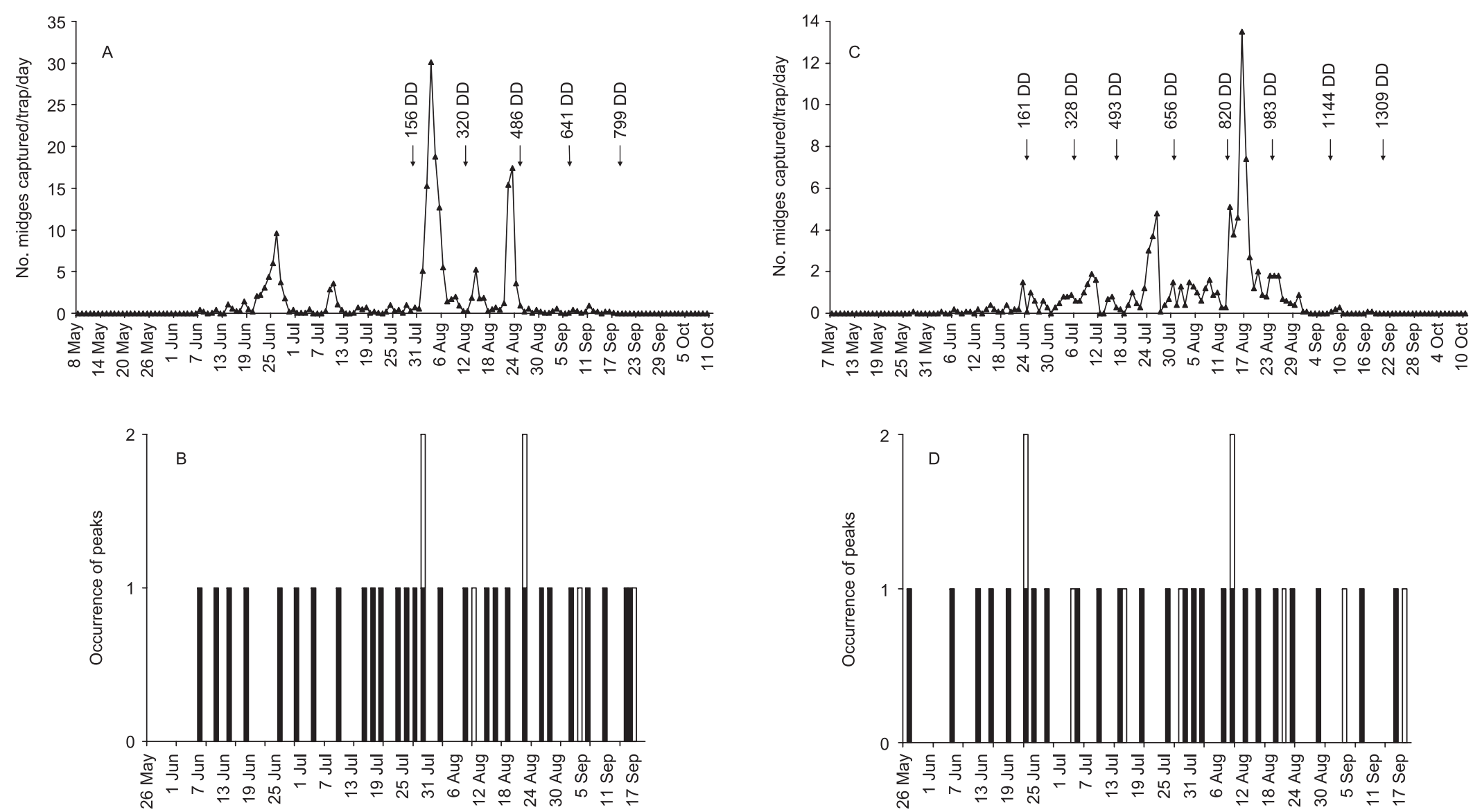

Figure 3 Comparison of observed adult swede midge (Contarinia nasturtii) captures in emergence traps in 2003 with predicted peaks according to the Contapré model for (A) Markham and (C) Stouffville. Arrows and degree-day values indicate the timing of emergence events predicted by the Contapré model. Comparison of the timing of observed peaks (black bars) based on emergence trap captures with predicted peaks (white bars) for (B) Markham and (D) Stouffville. 

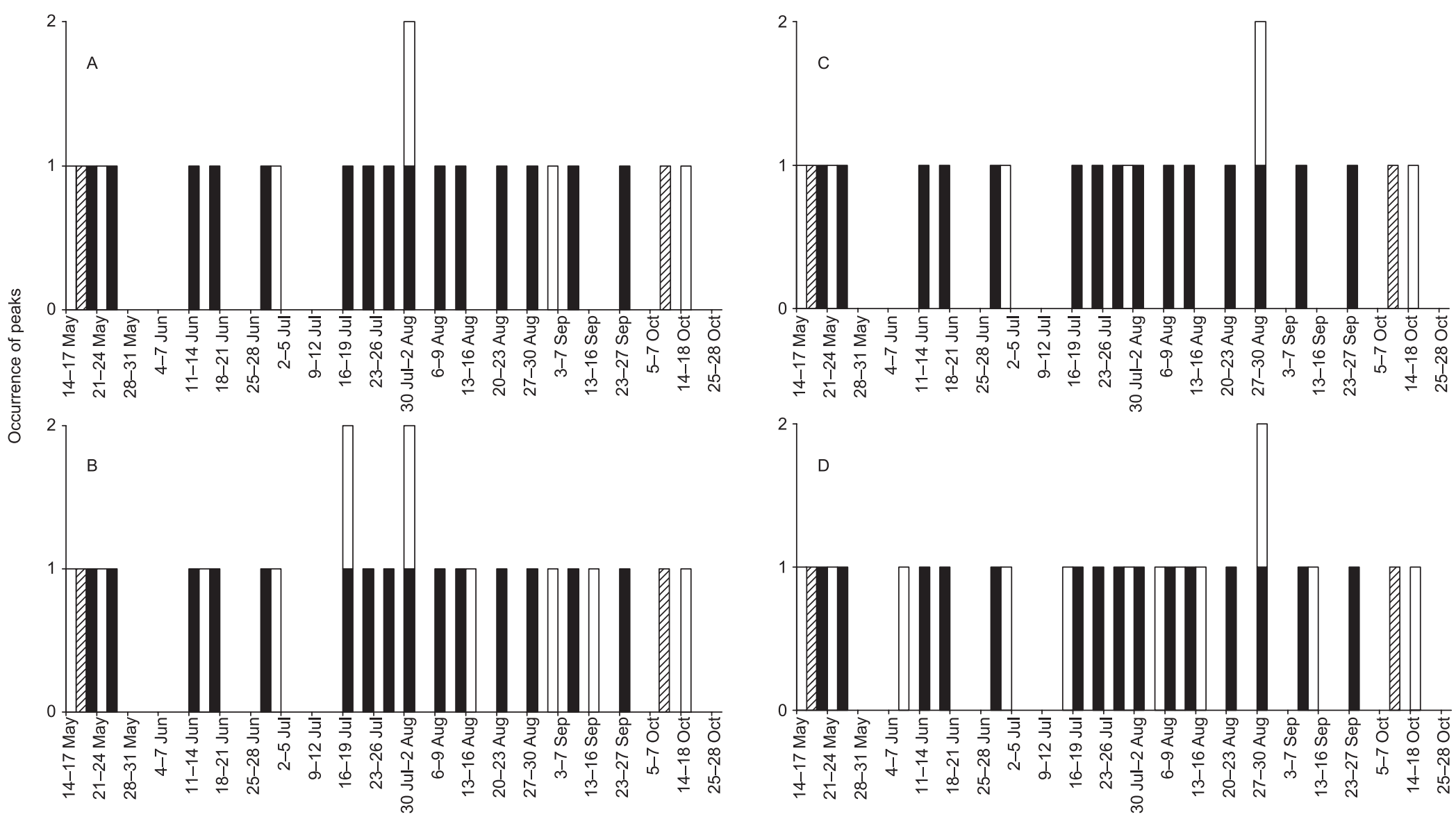

Figure 4 Comparison of the timing of observed (black bars) peaks of adult swede midge (Contarinia nasturtii) based on pheromone trap captures of males at Markham in 2004 with predicted peaks (white bars) using either the minimum temperature threshold for male pupae or the average threshold for males and females, and either one (60 diapause-development days from 1 January) or two (60 and 140 diapause-development days) emergence phenotypes. (A) Male threshold with single emergence phenotype. (B) Male threshold with two emergence phenotypes. (C) Average threshold with single emergence phenotype. (D) Average threshold with two emergence phenotypes. Bars with cross-hatching indicate first observed capture of midges, as this does not correspond with the first peak, and last observed capture of midges. 


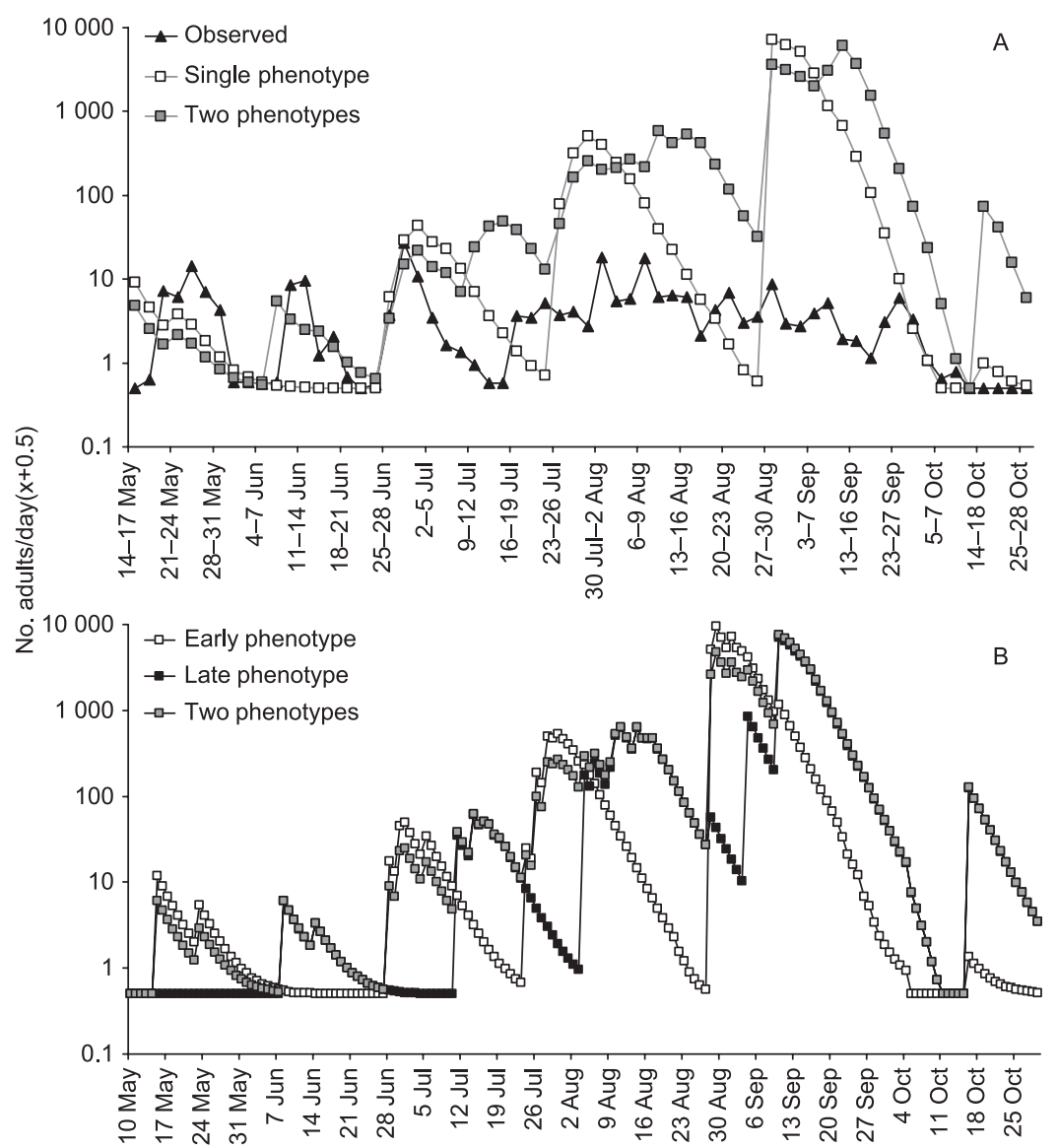

Figure 5 (A) Comparison of observed adult male swede midge (Contarinia nasturtii) captures $(x+0.5)$ in pheromone traps at Markham in 2004 with predicted adult populations using the average minimum temperature threshold for male and female pupae, and either one (60 diapause-development days from 1 January) or two (60 and 140 diapause-development days) emergence phenotypes. (B) Daily predicted numbers $(x+0.5)$ of swede midge adults based on the average threshold and the early (60 diapause-development days from 1 January), late (140 diapause-development days), or both emergence phenotypes.

for pupal development resulted in predicted peaks occurring within 3 days of $56.3 \%$ of the 16 observed peaks and within 5 days of $68.8 \%$ of observed peaks (Figure $4 \mathrm{~B}$ ). Using the average minimum temperature threshold for pupal development increased the accuracy rates to 68.8 and $75.0 \%$ of the 16 observed peaks being predicted within 3 and 5 days, respectively (Figure 4D). However, the goodness-of-fit values were higher for the model run with the male threshold $\left(\mathrm{r}^{2}=0.085, \mathrm{P}<0.02\right)$ than with the average threshold $\left(r^{2}=0.047, P=0.09\right)$.

Four observed peaks (16-18 June, 21-23 July, 20-23 August, and 23-27 September) were not predicted by the model with two emergence phenotypes when predicted numbers were pooled into trapping periods. However, there was very good overlap of predicted and observed population peaks in May, June, early July, and late September
(Figure 5A). In addition, if daily predicted numbers (Figure 5B) are examined, the model predicted peaks at 14 June and 24 July that were lost when data were grouped into trapping periods (Figure 5A). Addition of a third emergence phenotype with a requirement of 160 diapause development days resulted in an additional peak at 18-21 June, but did not contribute any other unique peaks, so this phenotype was excluded from the model.

Model validation. The MidgEmerge model using the average minimum temperature threshold for pupal development and two emergence phenotypes was first validated against observed population peaks from pheromone traps at Stouffville in 2004. Predicted peaks occurred within 3 days of $71.4 \%$ of the 14 observed peaks at Stouffville in 2004 and within 5 days of $85.7 \%$ of observed peaks (Figure $6 \mathrm{~A}$ ). The 

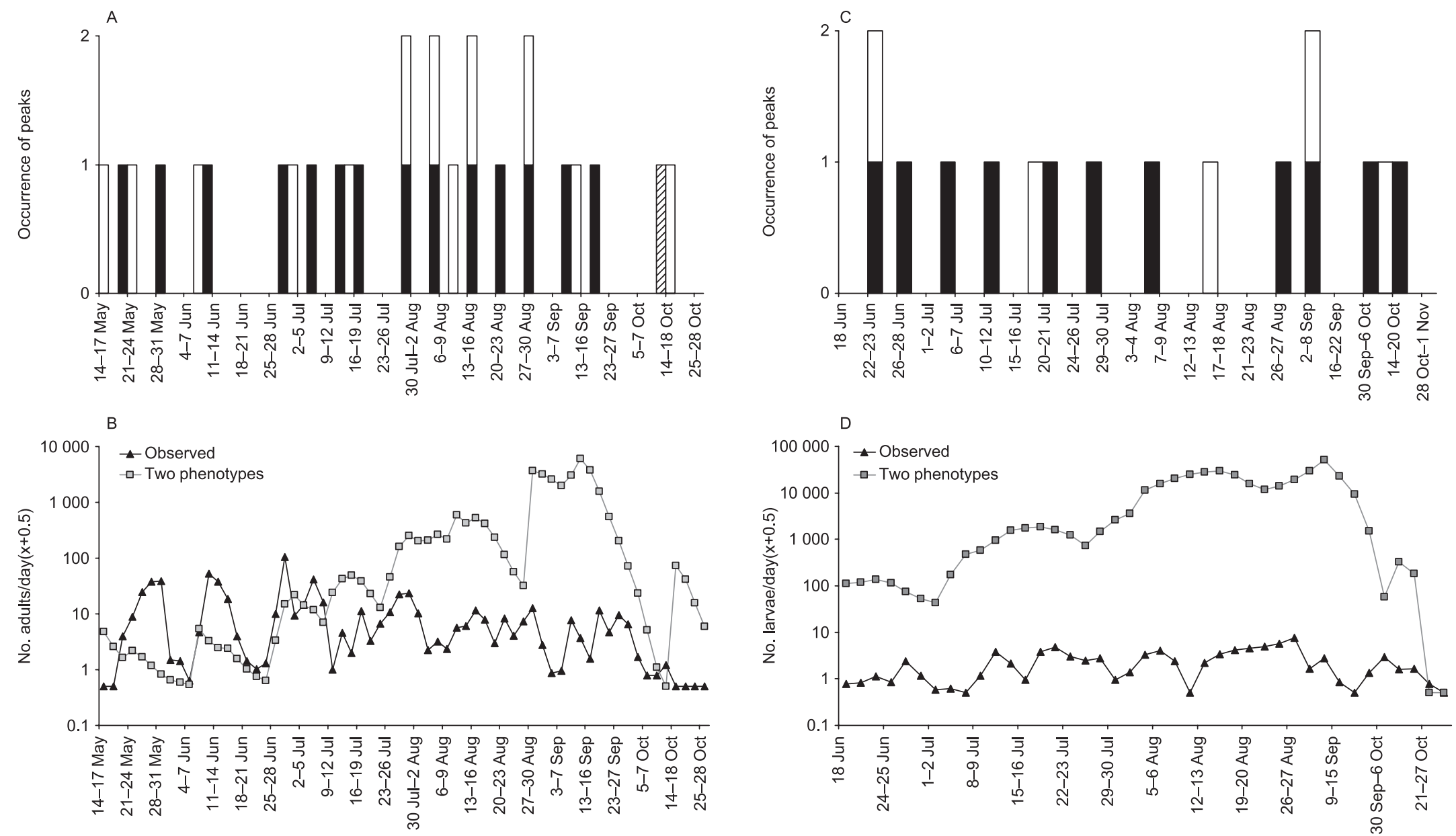

Figure 6 (A) Comparison of the timing of observed (black bars) peaks of adult swede midge (Contarinia nasturtii) based on pheromone trap captures at Stouffville in 2004 with predicted peaks (white bars) using the average minimum temperature threshold for males and females, and two (60 and 140 diapause-development days from 1 January) emergence phenotypes. Bar with cross-hatching indicates last observed capture of midges. (B) Comparison of observed swede midge pheromone trap captures $(x+0.5)$ at Stouffville in 2004 with predicted adult populations using the average threshold and two emergence phenotypes. (C) Comparison of the timing of observed (black bars) peaks of swede midge larvae at Laval in 2004 with predicted larval peaks (white bars) using the average threshold and two emergence phenotypes. (D) Comparison of observed larval swede midge populations $(x+0.5)$ at Laval in 2004 with predicted larval populations using the average threshold and two emergence phenotypes. 
goodness-of-fit value was significant $\left(\mathrm{r}^{2}=0.250, \mathrm{P}<0.0001\right)$. There was very good overlap of predicted and observed population peaks from May to mid-August, and in early October (Figure 6B). Of the peaks that were not wellpredicted when examined by trapping period (28-31 May, 5-7 July, 20-23 August, and 16-20 September), the daily model output predicted a peak at 5 July that was lost when data were grouped into trapping periods (Figure 5B).

The MidgEmerge model predicted five larval peaks at Laval during the comparison period in 2004 (Figure 6C). Predicted peaks occurred within 3 days of $45.5 \%$ of the 11 observed peaks and within 5 days of $63.6 \%$ of observed peaks. The goodness-of-fit value was very low and not significant $\left(\mathrm{r}^{2}=0.014, \mathrm{P}=0.47\right)$. The model predicted fewer peaks that were slower to increase and of longer duration than observed larval population peaks (Figure 6D).

The MidgEmerge model predicted 19 peaks at Markham and Stouffville in 2003 (Figure 7). The model predicted two emergence peaks occurring on 25 and 30 May. First emergence was observed on 7 June at Markham, and on 27 May at Stouffville. Predicted peaks occurred within 2 days of $65.4 \%$ of the 26 peaks observed in emergence traps at Markham in 2003, and within 5 days of $92.3 \%$ of observed peaks (Figure 7A). Observed peaks at Markham between 18-26 June, 16-20 July, and 7 and 11 September were not predicted by the model (Figure 7B). For Stouffville in 2003, predicted peaks occurred within 2 days of $62.5 \%$ of the 24 peaks observed in emergence traps and within 5 days of $83.3 \%$ of observed peaks (Figure 7C). Observed peaks at Stouffville between 15-25 June, 15-20 July, and 9 September were not predicted by the model (Figure 7D). However, the goodness-of-fit values were high and significant for both Markham $\left(\mathrm{r}^{2}=0.210, \mathrm{P}<0.0001\right)$ and Stouffville $\left(\mathrm{r}^{2}=0.328, \mathrm{P}<0.0001\right)$.

Examination of missing peaks. There were three periods (14-26 June, 16-20 July, and 7-11 September) where the model failed to predict peaks that were observed at Markham and Stouffville in 2003. Examination of the model output and weather data indicated an absence of pupae in the days preceding June 14-26, as all had graduated to the adult stage in the predicted peak beginning 10 June. For the July and September periods under examination, there was an absence of physiologically mature pupae ready to graduate to the adult stage in the days leading up to the observed peaks. In 2004, the model failed to predict one peak that was observed at Stouffville alone (28-31 May) and two that were observed at both Markham and Stouffville (20-23 August and 16-27 September). Examination of the model output and weather data indicated an absence of physiologically mature pupae in the days preceding these three observed peaks.
Number of generations. The model predicted the occurrence of 4.5 generations for each of the two emergence phenotypes in the Markham-Stouffville area in 2004 (Figure 5B). Adults predicted to occur in mid-October laid eggs, but these did not develop to diapause larvae prior to the onset of unfavourable weather conditions.

\section{Discussion}

Predictive modelling of the timing at which a particular life stage of a pest will occur can be a valuable component of an IPM programme. However, an inaccurate or unreliable model may lead to mistimed control actions, pest control failures, lost time and money, and the inappropriate use of insecticides. Simple averaging DD models, like the Contapré model, are considered to generally yield the poorest predictive results (Roltsch et al., 1999).

The Contapré model is not a reliable predictor of swede midge emergence under non-irrigated conditions in southern Ontario. The limited use of moisture parameters in the Contapré model may explain its relatively poor predictive ability. The Contapré model was developed (Bouma, 1996) and validated (Koch \& Gemmar, 2002) using population data from irrigated fields. In irrigated fields, developing swede midge would not be exposed to dry conditions and the effects of moisture on development can thus be ignored in models of irrigated systems. However, in non-irrigated fields, such as those in the present study, insect emergence may be delayed during periods of low or no rainfall. Delayed emergence due to low moisture has been reported in several cecidomyiids, including swede midge, Sitodiplosis mosellana (Géhin), and D. brassicae (Dry, 1915; Doane et al., 2002).

Spring weather conditions in Ontario did not always satisfy the requirements for the start of DD accumulations with the Contapré model. For example, at Stouffville in 2003 , the closest values $\left(17.3^{\circ} \mathrm{C}\right.$ with $16 \mathrm{~mm}$ of rain) to satisfy the commencement of DD accumulations occurred on 8 June. If the maximum temperature requirement for $20^{\circ} \mathrm{C}$ had been strictly adhered to, no DD would have been accumulated at this site in 2003. Predictions of first peaks did not begin until weeks after first swede midge emergence was observed.

For multi-voltine species, prediction events may be less reliable than predictions made for univoltine species due to generation overlaps and immigration or emigration events. However, a strong relationship was found between observed and predicted peaks for adults in several sites and years with the MidgEmerge model. MidgEmerge predicted 62.5 to $71.4 \%$ of adult peaks within 3 days and 75 to $92.3 \%$ within 5 days. Prediction of larval peaks was not as accurate, but this was likely due to the absence of 

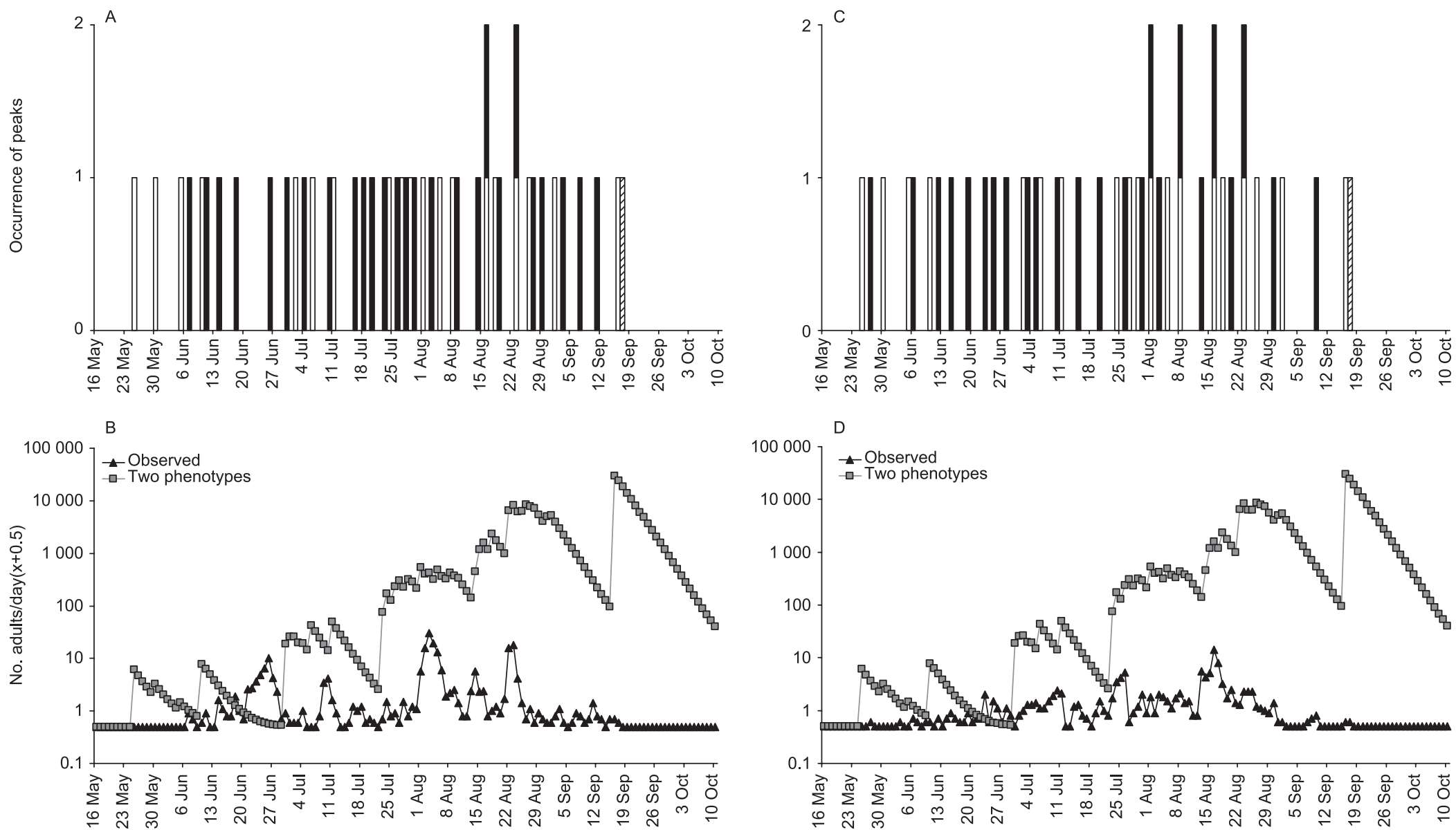

Figure 7 (A) Comparison of the timing of observed (black bars) peaks of adult swede midge (Contarinia nasturtii) on emergence trap captures at Markham in 2003 with predicted peaks (white bars) using the average minimum temperature threshold for males and females, and two (60 and 140 diapause-development days from 1 January) emergence phenotypes. (B) Comparison of observed swede midge emergence trap captures $(x+0.5)$ at Markham in 2003 with predicted adult populations using the average threshold and two emergence phenotypes. (C) Comparison of the timing of observed (black bars) peaks of swede midge adults based on emergence trap captures at Stouffville in 2003 with predicted peaks (white bars) using the average threshold and two emergence phenotypes. (D) Comparison of observed swede midge emergence trap captures ( $x+0.5)$ at Stouffville in 2003 with predicted adult populations using the average threshold and two emergence phenotypes. Bars with cross-hatching indicate last observed capture of midges. 
extrinsic mortality factors (natural enemies, pesticides, etc.) in the model that result in shorter larval peaks and more variable larval populations in the field.

The MidgEmerge model strongly supports the presence of two, and possibly three, emergence phenotypes of the swede midge. Use of a single phenotype in the model did not predict observed peaks accurately. Manipulation of various parameters indicates that the emergence phenotypes differ in diapause intensity (i.e., its relative duration; Danks, 1987) rather than having different response thresholds to environmental parameters. Differences among individuals in diapause intensity is largely explained by genetic differences, although prevailing photoperiods and temperatures during diapause induction may also influence diapause intensity (Danks, 1987). Factors controlling the induction and termination of diapause of the swede midge need further examination, but simulation of emergence phenotypes with the MidgEmerge model suggests that there are two emergence phenotypes requiring a total of 150 and 230 diapause development days (assuming diapause induction by early October). Similarly, the MidgEmerge model indicates that diapause induction may be triggered by photoperiods $\leq 13.5 \mathrm{~h}$ during the larval stage. The presence of a third emergence phenotype is suggested as there were several peaks not predicted by the use of two emergence phenotypes that could not be explained by environmental conditions. The predicted absence of physiologically mature pupae prior to these unpredicted peaks supports the existence of a third emergence phenotype. The swede midge (Rygg \& Braekke, 1980) and a number of other Contarinia species have been reported to engage in prolonged diapause (i.e., remain in diapause for more than one adverse season; Danks, 1987), but other accounts of multiple emergence phenotypes of swede midge are absent from the literature. The presence of multiple emergence phenotypes may act as a form of bet-hedging, allowing the population to prevail despite some emergence during adverse periods, and thus may contribute to the success of the swede midge as an invasive insect.

MidgEmerge predicted 4.5 generations of each of the two emergence phenotypes. Adult midges have not been observed in the field after mid-October, indicating that there are four generations of swede midge per year in southern Ontario. This number is supported by previous estimates of 3-5 overlapping generations (Hallett et al., 2007). Climate change is expected to lead to increasingly favourable conditions for swede midge in North America (Mika et al., 2008), and so a full fifth generation could occur in the future.

The MidgEmerge model performed as well or better with average developmental parameters for male and female pupae, than with male pupal parameters alone.
This result simplifies the operation of the model and means that the same parameters can be used to validate the model regardless of the trap type used to generate the population data against which it is to be compared. Predictive accuracy of the model in 2003 would likely have been higher, if validation had been conducted with pheromone trap, rather than emergence trap, data. Emergence traps capture insects emerging from a limited area of soil, and emergence trap data are thus vulnerable to microclimate variations and population variations related to the specific location of each trap. Pheromone trap captures can be as much as 30 times higher than emergence traps and thus provide a better representation of midge population dynamics (Hallett et al., 2007).

Predictive models can only be as reliable as the meteorological data used, due in part to the potential for microclimate effects. Evaluation of a previous version of this model (Goodfellow, 2005) found that predictive accuracy was higher with in-site than Environment Canada weather data, but that Environment Canada weather data still resulted in an acceptable level of predictive accuracy. The addition of the diapause larval stage to this model necessitated initialization of the model in early winter rather than in late spring, and so use of in-site weather data was precluded here. In-site weather data collection may not be practical for growers or crop scouts, but spatial variation in rainfall events can be considerable (Figures 1 and 2). For widespread use, it is recommended that the MidgEmerge model be operated using Environment Canada weather data, but supplementation with site-specific rainfall data is advisable.

The MidgEmerge model should provide growers with accurate information as to when adults or larvae will be in the field and allow optimal timing of insecticide applications. The acceptable level of predictive accuracy depends, at least in part, on the residual activity of insecticides being used. Assail (acetamiprid) and Matador (cyhalothrin lambda), the two products registered for use in Canada against swede midge, retain efficacy against swede midge for 7-10 days after application (RH Hallett \& MK Sears, unpubl.). Thus, prediction of peaks within 7 days of actual occurrence should be an acceptable level of accuracy. The MidgEmerge model predicted most swede midge peaks within 5 days of their actual occurrence, thus exceeding the desired level of accuracy. Effective control of first emerging adults and their offspring is considered critical to limiting swede midge population growth (International Swede Midge Task Force, 2005). The MidgEmerge model predicted first adult peaks several days in advance of their actual occurrence, thus providing growers with some lead time to prepare for taking a management action.

The MidgEmerge model could be used to provide regional predictions of swede midge peaks based on the 
location of weather stations or by crop consultants and individual growers to predict peaks at specific locations using in-site weather data. Temperature data and likelihood of precipitation events from 7-day weather forecasts could be used along with either regional or site-specific weather records to predict the likely occurrence of swede midge emergence in the coming week given various simulated rainfall events. Long-term normal data could also be used to generate values for expected precipitation over the next 7 days. MidgEmerge predictions could then be used to trigger daily monitoring of pheromone traps around anticipated peak events. Capture data from pheromone traps will provide growers with the information needed to determine whether a control strategy is warranted. For example, the MidgEmerge model may predict a peak emergence event, but previous insecticide events may have sufficiently reduced the swede midge population below damaging levels, making the insecticide application unnecessary. The combination of a predictive modelling tool and pheromone traps will enable growers to achieve more successful control of swede midge than has previously occurred as they will be able to accurately assess and time their control strategies.

\section{Acknowledgements}

The authors wish to thank D. Almas, D. Defilippis, and J. Hulshof for providing field research sites; Dr S.A. Marshall (University of Guelph) for emergence trap materials; F. Corlay (Université Laval) and Dr G. Boivin (Horticulture Research and Development Centre, Agriculture and Agri-Food Canada) for providing larval data; and the reviewers of a previous version of this article for their valuable and constructive comments. This research was supported by the Canada-Ontario R\&D Fund, the Ontario Ministry of Agriculture, Food and Rural Affairs (OMAFRA) Special Research Fund, the OMAFRA-University of Guelph Plants Program, the Ontario Fruit and Vegetable Growers' Association, and the Natural Sciences and Engineering Research Council of Canada.

\section{References}

Barnes HF (1946) Gall Midges of Economic Importance. I. Gall Midges of Root and Vegetable Crops. Crosby Lockwood \& Son Ltd, London, UK.

Borchert DM, Stinner RE, Walgenbach JF \& Kennedy GG (2004) Oriental fruit moth (Lepidoptera: Tortricidae) phenology and management with methoxyfenozide in North Carolina apples. Journal of Economic Entomology 97: 1353-1364.

Bouma E (1996) Contapré, prototype of a model for prediction of emerging of the swede midge (Contarinia nasturtii). SPReport, Danish Institute of Plant and Soil Science 15: 25-30.
Broatch JS, Dosdall LM, Clayton GW, Harker KN \& Yang RC (2006) Using degree-day and logistic models to predict emergence patterns and seasonal flights of the cabbage maggot and seed corn maggot (Diptera: Anthomyiidae) in canola. Environmental Entomology 35: 1166-1177.

Canadian Food Inspection Agency (2002) Plant Health Risk Assessment: Contarinia nasturtii (Kieffer), the swede midge. PHPD Request: 2002-04; File No. 31403. Plant Health Risk Assessment Unit, Canadian Food Inspection Agency.

Canadian Food Inspection Agency (2007) Swede Midge - Ontario 2007 Map. http://www.inspection.gc.ca/english/sci/surv/2007 maps/cnqzon2007e.shtml. CFIA Plant Health Division.

Canadian Food Inspection Agency (2008) Swede Midge Contarinia nasturtii. http://www.inspection.gc.ca/english/plaveg/ pestrava/connas/connase.shtml. CFIA Plant Health Division.

Danks HV (1987) Insect Dormancy: An Ecological Perspective. Biological Survey of Canada (Terrestrial Arthropods), Ottawa, Canada.

Davis PM \& Pedigo LP (1991) Economic injury levels for management of stalk borer (Lepidoptera: Noctuidae) in corn. Journal of Economic Entomology 84: 290-293.

Doane JF, Braun MP, Olfert OO, Affolter F \& Carl K (2002) Sitodiplosis mosellana (Géhin), orange wheat blossom midge (Diptera: Cecidomyiidae). Biological Control Programmes in Canada, 1981-2000 (ed. by PG Mason \& JT Huber), pp. 246249. CABI, Wallingford, UK.

Dry FW (1915) An attempt to measure the local and seasonal abundance of the swede midge in parts of Yorkshire over the years 1912 to 1914. Annals of Applied Biology 2: 81-108.

Environment Canada (2005) Canadian Climate Data Online. http://www.climate.weatheroffice.ec.gc.ca/climateData/ canada_e.html.

Felt EP (1925) Key to Gall Midges (A resumé of studies I-VII, Itonididae). New York State Museum Bulletin 257.

Frey JE, Frey B \& Baur R (2004) Molecular identification of the swede midge (Diptera: Cecidomyiidae). The Canadian Entomologist 136: 771-780.

Goodfellow SA (2005) Population Dynamics and Predictive Modelling of the Swede Midge, Contarinia nasturtii (Kieffer). MSc Thesis, University of Guelph, Guelph, Ontario, Canada.

Hallett RH, Goodfellow SA \& Heal JD (2007) Monitoring and detection of the swede midge (Diptera: Cecidomyiidae). The Canadian Entomologist 139: 700-712.

Hallett RH \& Heal JD (2001) First nearctic record of the swede midge (Diptera: Cecidomyiidae), a pest of cruciferous crops from Europe. The Canadian Entomologist 133: 713-715.

International Swede Midge Task Force (2005) 2005 Interim Best Management Practices to Control the Swede Midge (Contarinia nasturtii Kieffer); available at http://www.omafra.gov.on.ca/ english/crops/facts/bmp_swedemidge.htm.

Koch I \& Gemmar A (2002) Untersuchungen über das Auftreten und die Prognose der Kohldrehherzmücke (Contarinia nasturtii Kieffer) an Brokkoli in der Vorderpfalz. Pflanzenschutzberichte 60: 37-43.

Maywald GF, Kriticos DJ, Sutherst RW \& Bottomley W (2003) DYMEX v2 Model Builder User's Guide. Hearne Scientific Software, Melbourne, Victoria, Australia. 
Maywald GF, Sutherst RW \& Bourne A (2004) DYMEX v2 Model Simulator User's Guide. Hearne Scientific Software, Melbourne, Victoria, Australia.

Mika A, Weiss RM, Olfert O, Hallett RH \& Newman JA (2008) Will climate change be beneficial or detrimental to the invasive swede midge in North America? Contrasting predictions using climate projections from different general circulation models. Global Change Biology 14: 1721-1733.

New M, Hulme M \& Jones M (1999) Representing twentiethcentury space-time climate variability. Part I: development of a 1961-90 mean monthly terrestrial climatology. Journal of Climate 12: 829-856.

Olfert OO, Hallett RH, Weiss RM, Soroka JJ \& Goodfellow S (2006) Potential distribution and relative abundance of swede midge, Contarinia nasturtii (Diptera: Cecidomyiidae), an invasive pest in Canada. Entomologia Experimentalis et Applicata 120: 221-228.

Pest Management Regulatory Agency (2006) Product Information Label Search; available at http://www.pmra-arla.gc.ca/english/ pubreg/productinformation-e.html.

Readshaw JL (1961) The Biology and Ecology of the Swede Midge, Contarinia nasturtii (Kieffer) (Diptera; Cecidomyiidae). PhD thesis, University of Durham, Durham, UK.

Readshaw JL (1966) The ecology of the swede midge, Contarinia nasturti (Kieffer) (Diptera; Cecidomyiidae). I. Life-history and influence of temperature and moisture on development. Bulletin of Entomological Research 56: 685-700.

Ridsdill-Smith J, Parvi C, De Boer B \& Kriticos DJ (2005) Predictions of summer diapause in the redlegged earth mite, Halotydeus destructor (Acari: Penthaleidae) in Australia. Journal of Insect Physiology 51: 717-726.

Roltsch WJ, Zalom FG, Strawn AJ, Strand JF \& Pitcairn MJ (1999) Evaluation of several degree-day estimation methods in California climates. International Journal of Biometeorology 42: 169-176.

Rygg TD \& Braekke HP (1980) Swede midge (Contarinia nasturtii Kieffer) (Diptera: Cecidomyiidae): investigations on biology, symptoms of attack and yield. Meldinger fra Norges landsbrukshøgskole 59: 1-9.

SAS Institute (1999) SAS/STAT for Windows, Version 8.1. Cary, NC, USA.

Smith K (1951) A Text Book of Agricultural Entomology. Cambridge University Press, London, UK.

Stokes BM (1953) Biological investigations into the validity of Contarinia species living on Cruciferae, with special reference to the swede midge, Contarinia nasturtii (Kieffer). Annals of Applied Biology 40: 726-741.

Sutherst RW, Maywald GF, Bottomley W \& Bourne A (2004) CLIMEX $^{\mathrm{TM}}$ Version 2 User's Guide. Hearne Scientific Software, Melbourne, Australia.

Taylor TH (1912) Cabbage-top in swedes. The University of Leeds and the Yorkshire Council for Agricultural Education 82: 1-21.

Yamamura K (1999) Transformation using $(x+0.5)$ to stabilize the variance of populations. Researches on Population Ecology 41: $229-234$. 